\title{
NAVIGASI GPS DENGAN REMINDER WAKTU SHOLAT MENGGUNAKAN ALGORITMA A* DENGAN PERTIMBANGAN JARAK, INDEX KEMACETAN DAN INDEX PREFERENSI MASJID : STUDI KASUS DARI CILEDUG KE SENAYAN
}

\author{
Rifqi Riadhi ${ }^{1}$ \\ Universitas Muhammadiyah Tangerang / Fakultas Teknik, \\ Program Studi Informatika \\ JI. Perintis Kemerdekaan 1/33 Cikokol Kota Tangerang TLP. 55793251, 55772949, 55793802, \\ 55736926 \\ Email : rifqiriadhi07@gmail.com
}

\begin{abstract}
ABSTRAK
Jumlah kendaraan bermotor di kota besar terus meningkat yang mengakibatkan tingginya tingkat kemacetan di kota besar. Salah satu indikator meningkatnya tingkat kemacetan tersebut adalah tingginya aktifitas dari warga di kota besar. Seperti yang diketahui bahwa kebanyakan para pekerja yang bekerja di kota besar berasal dari kota - kota disekitar kota besar tersebut. Jakarta sebagai Ibu Kota memiliki tingkat kemacetan dan kepadatan aktifitas yang tinggi. Sayangnya di tengah kondisi seperti itu menyebabkan umat muslim di Jakarta kesulitan dalam menjalankan kewajibannya beribadah sholat 5 waktu. Untuk itulah diperlukan adanya reminder waktu sholat yang dapat memfasilitasi umat muslim agar dapat menjalankan kewajibannya dengan baik. Berdasarkan penjelasan sebelumnya, maka penelitian ini akan fokus didalam mengembangkan sistem navigasi GPS berbasis reminder waktu sholat dengan memanfaatkan algoritma $A^{*}$ untuk mendapatkan lokasi masjid terbaik, dengan parameter jarak, index kemacetan dan index preferensi masjid. Hasil penelitian ini menghasilkan sebuah sistem navigasi GPS dengan reminder waktu sholat yang memberikan lokasi masjid terbaik dan memandu pengguna ke lokasi masjid tersebut.
\end{abstract}

Kata kunci : reminder, algoritma A*, GPS, Google Maps, Google Maps API, web service, latitude, longitude

\section{ABSTRACT}

Duration of Motor Vehicles in big cities Keep INCREASED that results in a high level of congestion in big cities. One indicator is the increasing level of congestion is higher activity From People in big cities. As Yang discovered that most of the workers Yang WORK in the big city comes from the town - the town around the big cities. Jakarta as the capital city has the level of congestion and density of activity Yang High. Unfortunately, in the Middle of conditions such as ITU cause, Muslims in Jakarta difficulty carrying out its obligations Beribadah hearts prayer 5 time. That's necessary to review their prayer time reminders what can be facilitated, Muslims that can be run obligations WITH Good. Based on the previous explanations, reminders Then Singer Research will focus within develop Time-Based GPS Navigation System prayer WITH utilizing the $A$ * algorithm to review LOCATION get Best mosque, parameter WITH jatropha, congestion index and the index of the mosque Preferences. Results Singer produces GPS Navigation Systems WITH AN Time reminder mosque prayer that gives LOCATION Best And guide users LOCATION Into the mosque.

Keywords: reminder, algoritma A*, GPS, Google Maps, Google Maps API, web service, latitude, longitude 


\section{Introduction}

Perkembangan umat muslim didunia sangat pesat, tercatat pada tahun 2013 mencapai $22,43 \%$ dari 7.021.836.029 jumlah penduduk dunia dengan rata-rata pertahun mengalami perkembangan sebesar 1,8\% [19].

Indonesia sebagai salah satu negara yang mayoritas penduduknya adalah umat muslim menyumbang $12,7 \%$ dari total jumlah umat muslim dunia. Perkembangan umat muslim di Indonesia sendiri mencapai jumlah 207.176.162 pada tahun 2010 [3].

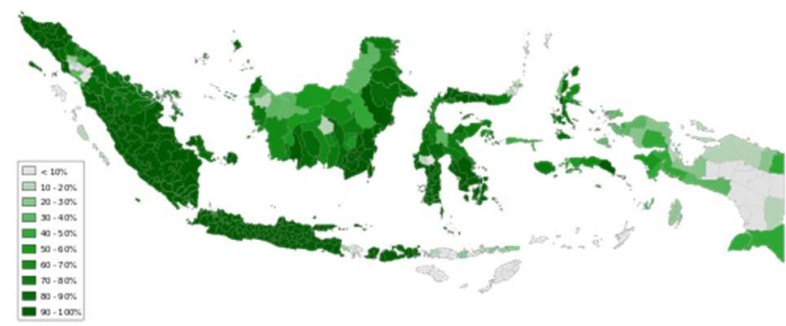

Gambar I : Peta Persebaran Umat Islam Di Indonesia Sensus Th 2010 [3].

Jumlah kendaraan yang ada di kota besar didunia dewasa ini mendorong meningkatnya tingkat kemacetan, sehingga diketahui bahwa index kemacetan dikota besar dunia pada tahun 2014 ini seperti Milan (33.8), Los Angeles $(31,2)$ dan Paris $(24,2)$ [11].

\begin{tabular}{llrrrr}
\multicolumn{3}{l}{ Most Congested Metros: Top 10 } & & & \\
& & T12 Months & This Month & This Month LY \\
\hline Milano & 1 & 33.8 & 27.0 & 19.4 \\
\hline Bruxelles & 2 & 33.3 & 31.5 & 32.9 \\
\hline Antw erpen & 3 & 31.4 & 32.3 & 29.3 \\
\hline Honolulu & 4 & 31.3 & 39.7 & 31.8 \\
\hline Los Angeles & 5 & 31.2 & 28.5 & 28.8 \\
\hline London commut.. & 6 & 30.1 & 30.6 & 25.4 \\
\hline San Francisco & 7 & 26.8 & 23.7 & 21.3 \\
\hline Gr. Manchester & 8 & 25.9 & 28.7 & 24.4 \\
\hline Paris & 9 & 24.2 & 19.4 & 22.5 \\
\hline Rotterdam & 10 & 23.1 & 21.4 & 22.4 \\
\hline
\end{tabular}

Gambar II : Index Kemacetan Di Kota Besar Tahun 2014 [11].

Salah satu indikator meningkatnya tingkat kemacetan tersebut adalah tingginya aktifitas dari warga dikota besar. Seperti yang diketahui bahwa kebanyakan para pekerja yang bekerja di kota besar berasal dari kota - kota disekitar kota besar tersebut.

Jakarta sebagai ibukota Indonesia, tingginya tingkat kemacetan dan tingginya aktifitas diwilayah tersebut pun diketahui mengalami peningkatan sebesar $20 \%$ pada tahun 2014 [14]. Hal tersebut membuat Jakarta menjadi salah satu kota tersibuk di Indonesia.

Disisi lain, setiap Muslim diharuskan sholat tepat pada waktunya. Masalah muncul ketika umat Muslim dikota besar dihadapkan pada kesibukan yang tinggi di tengah kemacetan kota besar yang terus meningkat. Hal tersebut mendorong dibutuhkannya mekanisme pengingat waktu sholat yang dapat memfasilitasi umat Muslim agar dapat menjalankan kewajibannya dengan baik.

Sebagai Ibukota sudah tentu Jakarta sangat sibuk sehingga akses menuju Jakarta dari kota-kota sekitarnya sangat padat. Salah satu rute terpadat di Jakarta adalah rute Ciledug - Senayan. Rute ini menghubungkan Tangerang dan Jakarta ,tepatnya Jakarta Selatan.

A* adalah algortima yang dapat memberikan solusi global optima terhadap permasalah pencarian rute dibandingkan algoritma Best First Search (BFS). Berdasarkan paparan latar belakang diatas, penulis mengajukan navigasi gps dengan reminder waktu sholat mengunakan algoritma $A^{*}$ dengan pertimbangan jarak, index kemacetan dan index preferensi masjid : studi kasus Ciledug - Senayan sebagai alternatif solutif terhadap masalah tersebut diatas.

\section{Related Work}

\section{A. Google Maps}

Google Maps adalah layanan aplikasi peta online yang disediakan oleh Google secara gratis.Layanan peta Google Maps secara resmi dapat diakses melalui situs http://maps.google.com. Pada situs tersebut dapat dilihat informasi geografis pada hampir semua permukaan di bumi kecuali daerah kutub utara dan selatan. Layanan ini dibuat sangat interaktif, karena di dalamnya peta dapat digeser sesuai keinginan pengguna, mengubah level zoom, serta mengubah tampilan jenis peta.

Google Maps mempunyai banyak fasilitas yang dapat dipergunakan misalnya pencarian lokasi dengan memasukkan kata kunci, kata kunci yang dimaksud seperti nama tempat, kota, atau jalan, fasilitas lainnya yaitu perhitungan rute perjalanan dari satu tempat ke tempat lainnya.

Google Maps dibuat dengan menggunakan kombinasi dari gambar peta, database, serta obyek-obyek interaktif yang dibuat dengan bahasa pemrograman HTML, Javascript dan AJAX, serta beberapa bahasa pemrograman lainnya.

Gambar-gambar yang muncul pada peta merupakan hasil komunikasi dengan database pada web server Google untuk menampilkan gabungan dari potongan-potongan gambar yang diminta. Keseluruhan citra yang ada diintegrasikan ke dalam database pada Google Server, yang nantinya akan dapat dipanggil sesuai kebutuhan permintaan. Bagian- bagian gambar map merupakan gabungan dari potongan gambar-gambar bertipe PNG yang disebut tile yang berukuran $256 \times 256$ pixel seperti gambar berikut. 


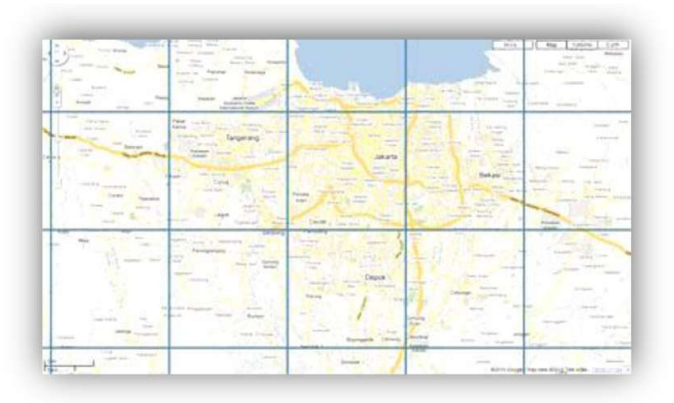

Gambar III. Pembagian Gambar Peta Sebesar 256 x 256 pixel [22].

\section{B. Global Positioning System (GPS)}

GPS (Global Positioning System) adalah sistem satelit navigasi penentuan posisi yang dikelola oleh Amerika Serikat. Sistem ini didesain untuk memberikan posisi dan kecepatan tiga dimensi serta informasi mengenai waktu secara kontinyu di seluruh dunia tanpa bergantung waktu dan cuaca [9].

Secara umum ada tiga segmen dalam sistem GPS ,yaitu segmen sistem control, segmen satelit dan segmen pengguna. Segmen sistem control berfungsi mengontrol dan memantau operasional satelit dan memastikan bahwa satelit berfungsi sebagaimana mestinya. Segmen pengguna terdiri dari para pengguna satelit GPS di manapun berada. Dalam hal ini alat penerima sinya GPS (GPS Receiver) diperlukan untuk menerima dan memproses sinyal-sinyal dari satelit GPS untuk digunakan dalam penentuan posisi, kecepatan dan waktu komponen utama dari suatu receiver GPS secara umum adalah antena dengan pre-amplifier, bagian RF dengan pengidentifikasi sinyal dan pemproses sinyal, pemroses mikro untuk pengontrolan receiver, data sampling dan pemroses data (solusi navigasi), osilator presisi, catu daya, unit perintah ,tampilan dan memori serta perekam data.

\section{Algoritma A*}

A* (dibaca "A bintang / A star") adalah suatu algoritma pencarian di komputer yang banyak digunakan untuk mencari rute atau jalur dari satu titik ketitik lainnya. Pendekatan yang digunakan oleh algoritma ini adalah pendekatan heuristik $\mathrm{h}(\mathrm{x})$ yang memberikan nilai ke setiap titik node $\mathrm{x}$ dengan memperkirakan rute terbaik yang dapat dilalui sehingga mendapatkan jalur yang paling efisien. Algoritma ini pertama kali ditemukan pada tahun 1968 oleh Peter Hart, Nils Nilsson dan Bertram Raphael [10].

Beberapa terminologi dasar yang terdapat pada algoritma ini adalah :

a) Starting point adalah sebuah terminologi posisi awal sebuah benda.

b) A adalah simpul yang sedang dijalankan algortima pencarian jalan terpendek. c) Simpul adalah petak-petak kecil sebagai representasi dari areapathfinding. Bentuknya dapat berupa persegi,lingkaran, maupun segitiga.

d) Open list adalah tempat menyimpan data simpul yang mungkin diakses dari starting point maupun simpul yang sedang dijalankan.

e) Closed list adalah tempat menyimpan data simpul sebelum A yang juga merupakan bagian dari jalur terpendek yang telah berhasil didapatkan.

f) Nilai (F) adalah nilai yang diperoleh dari penjumlahan nilai $G$, jumlah nilai tiap simpul dalam jalur terpendek dari starting point ke $\mathrm{A}$, dan $\mathrm{H}$, jumlah nilai perkiraan dari sebuah simpul ke simpul tujuan.

g) Simpul tujuan yaitu simpul yang dituju.

h) Rintangan adalah sebuah atribut yang menyatakan bahwa sebuah simpul tidak dapat dilalui oleh A.

D. Tinjauan Studi

Tinjauan Studi dalam penelitian ini mengacu pada beberapa penelitian terkait yang sudah dilakukan sebelumnya, antara lain:

Tabel I : Ringkasan Penelitian Terkait

\begin{tabular}{|c|c|c|}
\hline Paper & Judul Penelitian & Metode \\
\hline $\begin{array}{c}\text { [Swati } \\
2012]\end{array}$ & $\begin{array}{l}\text { GPS Integrated } \\
\text { Navigation System }\end{array}$ & $\begin{array}{l}\text { Melakukan pencarian } \\
\text { rute terpedek } \\
\text { menggunakan } \\
\text { algoritma Search Path } \\
X-Y\end{array}$ \\
\hline $\begin{array}{l}\text { [Marwan } \\
\text { 2004] }\end{array}$ & $\begin{array}{l}\text { Real Time GPS } \\
\text { Navigation System }\end{array}$ & $\begin{array}{l}\text { Melakukan pencarian } \\
\text { rute terpedek } \\
\text { menggunakan } \\
\text { algoritma Dijkstra }\end{array}$ \\
\hline $\begin{array}{l}\text { [Bagrech } \\
\text { a 2012] }\end{array}$ & $\begin{array}{lr}\text { Android } & \text { Application } \\
\text { Using } & \text { GPS } \\
\text { Navigation } & \end{array}$ & $\begin{array}{l}\text { Melakukan pencarian } \\
\text { rute terpedek } \\
\text { menggunakan } \\
\text { algoritma } A^{*} \text { algorithm }\end{array}$ \\
\hline $\begin{array}{c}\text { [Rathiah } \\
\text { 2011] }\end{array}$ & $\begin{array}{l}\text { Mosque Tracking on } \\
\text { Mobile GPS and } \\
\text { Prayer Times } \\
\text { Synchronization for } \\
\text { Unfamiliar Area }\end{array}$ & $\begin{array}{l}\text { Melakukan pencarian } \\
\text { rute terpedek } \\
\text { menggunakan } \\
\text { algoritma Fuzzy strong } \\
\text { tracking unscented } \\
\text { Kalman filter }\end{array}$ \\
\hline $\begin{array}{l}\text { [Rifqi, } \\
\text { Tesis] }\end{array}$ & $\begin{array}{lr}\text { Navigasi } & \text { GPS } \\
\text { dengan } & \text { Reminder } \\
\text { Waktu } & \text { Sholat } \\
\text { Mengunakan } & \\
\text { Algoritma } A^{*} \text { dengan } \\
\text { Pertimbangan Jarak, } \\
\text { Index Kemacetan } \\
\text { dan Index Preferensi } \\
\text { Masjid: } \\
\text { Studi Kasus dari } \\
\text { Ciledug ke Senayan }\end{array}$ & $\begin{array}{l}\text { Melakukan pencarian } \\
\text { rute terpedek } \\
\text { menggunakan } \\
\text { algoritma } A^{*} \text { dengan } \\
\text { pertimbangan jarak, } \\
\text { parameter index } \\
\text { kemacetan dan index } \\
\text { preferensi masjid. }\end{array}$ \\
\hline
\end{tabular}


Penelitian-penelitian terkait di atas memiliki tujuan yang sama dengan penelitian ini yaitu mengefisiensikan penggunaan listrik dalam hal biaya, mengefisiensikan waktu, mengurangi potensi kelalaian dan kejahatan, serta mengontrol keadaan rumah. Namun perbedaan yang mendasar adalah bahwa penelitian ini menggunakan algoritma Divide and Conquer dan Free Space Path Loss. Jadi dengan metode ini, selain dapat mengontrol dan memonitoring, aplikasi ini juga dapat meng-handdle secara otomatis.

\section{Methodology}

Menurut kamus besar bahasa Indonesia, penelitian adalah suatu kegiatan mengumpulkan, mengolahan, analisa dan penyajian data yang dilakukan dengan sistematis dan objektif untuk memecahkan suatu persoalan atau menguji suatu hipotesis untuk mengembangkan prinsip-prinsip umum. Adapun metode yang umum digunakan yaitu, tindakan penelitian, eksperimen, studi kasus dan survei [4].

Metode experimen dapat dibagi menjadi 2 tipe yaitu, experimen absolut dan experimen komparatif. Experimen komparatif dilakuan dengan membandingkan 2 hal yang berbeda dengan melihat hasil-hasil statistik dari kedua hal yang dibandingkan tersebut untuk kemudian mengambil yang terbaik diantara keduannya. Sedangkan experimen absolut dilakukan dengan mengkaji dampak dan hasil dari sebuah percobaan [13].

Berdasarkan paparan tersebut, penelitian pada tesis ini dapat dikategorikan sebagai penelitian experiment komparatif . Eksperimen dalam penelitian ini bertujuan untuk mencari lokasi masjid terbaik menggunakan algoritma $\mathrm{A}^{*}$ dengan beberapa nilai index parameter seperti index kemacetan, kecepatan ,waktu, jarak dan index preferensi masjid. Pada penelitian ini pertama kali harus mendapatkan latitude dan logitude serta jarak lokasi saat ini ke lokasi tujuan awal memanfaatkan google maps API, kemudian mengambil nilai kecepatan saat ini yang kemudian nilai tersebut dikirim ke server via web service, yang kemudian nilai tersebut diproses algoritma $A^{*}$ sehingga menghasilkan koordinat lokasi masjid yang terbaik.

\section{A. Pemilihan Sampel}

Data primer adalah data yang dikumpulkan pertama kali untuk melihat apa yang terjadi pada penerapan nyata. Sedangkan data sekunder adalah data yang sebelumnya pernah dibuat seseorang baik yang dipublikasikan maupun yang tidak [13]. Data primer dapat berupa opini subjek secara individu maupun kelompok, hasil observasi terhadap suatu benda, kejadian atau kegiatan dan hasil pengujian.

Adapun pada penelitian ini metode pengumpulan data yang digunakan adalah metode pengumpulan data primer yang mana data tersebut didapatkan menggunakan google maps untuk mendapatkan koordinat latitude dan longitude suatu tempat dalam hal ini lokasi masjid sepanjang jalur ciledug - senayan. Serta kondisi jalan untuk mendapatkan sampel data yang kemudian diklasifikasikan kembali menjadi macet, lancar dan sebagainya.

\section{B. Arsiteksur Sistem}

Dalam penelitian ini, perancangan sistem navigasi GPS dengan reminder waktu sholat mengunakan mengunakan Algoritma $A^{*}$ dengan pertimbangan jarak, index kemacetan dan index preferensi masjid, untuk mendapatkan hasil pencarian terbaik berdasarkan perhitungan algoritma tersebut. Metode komunikasi yang digunakan adalah client-server di mana client menggunakan smartphone android dan server menggunakan laptop atau komputer sebagai pemroses data yang dinput dan yang berasal dari database dengan menggunakan Algoritma $\mathrm{A}^{*}$. Data yang ada di database merupakan data lokasi masdjid dan index pendukung lainnya yang sudah dikumpulkan sebelumnya.

Berikut ini adalah bentuk arsitektur sistem navigasi GPS dengan reminder waktu sholat mengunakan Algoritma A* dengan pertimbangan jarak, index kemacetan dan index preferensi masjid, studi kasus dari Ciledug Ke Senayan.

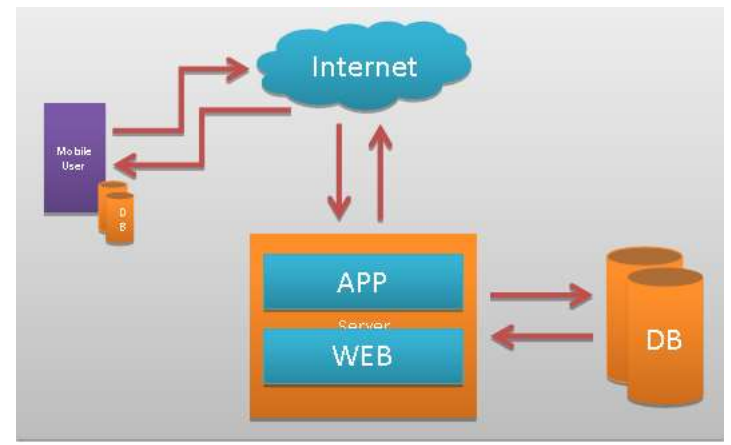

Gambar IV : Arsitektur Sistem

Secara proses bagaimana sistem dapat menghasilkan output lokasi masjid dapat dilihat pada gambar berikut. mpongri

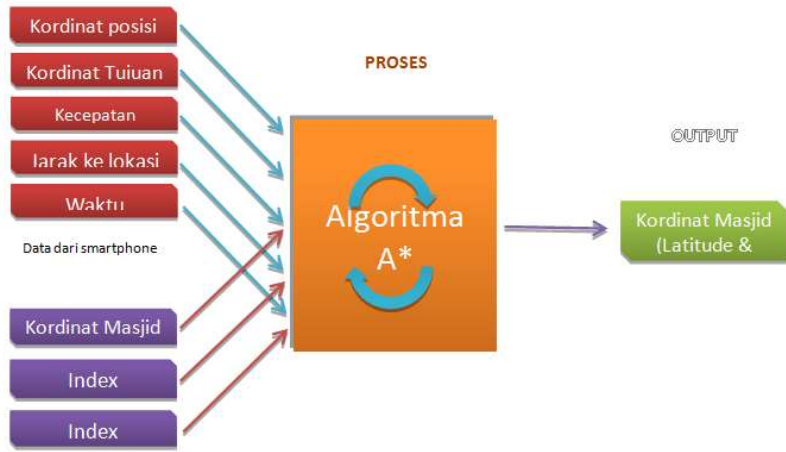

Data dari Database

Gambar V : Diagram Proses dari Sistem 
Diagram tersebut menggambarkan bagaimana data yang berasal dari smartphone dan database sebagai input, kemudian diproses oleh server untuk mencari lokasi masjid menggunakan algoritma $A^{*}$.

\section{Rancangan Sistem}

Rancangan untuk penelitian ini pada awalnya akan mengambil koordinat posisi pengguna saat ini dan koordinat tujuan awal yang ditentukan oleh pengguna. Pada tahap ini sistem akan mengirimkan koordinat (latitude dan longitude) pengguna saat ini, koordinat (latitude dan longitude) tujuan, jarak ke tujuan, kecepatan dan waktu sholat ke server menggunakan web service. Pada posisi ini pemrograman yang digunakan menggunakan bahasa pemrograman Android (java) yang memanfaatkan API dari Google yaitu Google API.
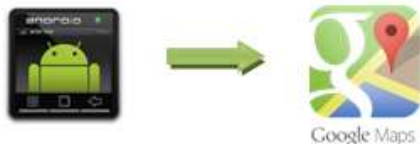

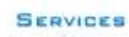

SERVICE:

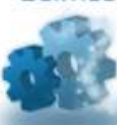

Gambar VI : Proses Pengambilan Koordinat

Di sisi server kemudian data tersebut akan diproses dengan algoritma $\mathrm{A}^{*}$. Pertama kali sistem akan mengambil data koordinat (latitude dan longitude) lokasi masjid dari database yang jaraknya tidak lebih besar dari nilai jarak yang dikirimkan oleh client (jarak lokasi saat ini ke tujuan awal), kemudian sistem mengambil nilai index preferensi dan index kemacetan dari database berdasarkan data masjid tersebut.

\begin{tabular}{cl}
\multicolumn{2}{c}{ Tabel II : Index Kemacetan } \\
\hline Value & \multicolumn{1}{c}{ Keterangan } \\
\hline $\mathbf{1}$ & Sangat Lancar \\
$\mathbf{2}$ & Lancar \\
$\mathbf{3}$ & Ramai Lancar \\
$\mathbf{4}$ & Macet \\
$\mathbf{5}$ & sangat Macet \\
\hline
\end{tabular}

Tabel III : Index Preferensi

\begin{tabular}{cl}
\hline Value & \multicolumn{1}{c}{ Keterangan } \\
\hline $\mathbf{1}$ & Sangat Direkomendasikan \\
$\mathbf{2}$ & Direkomendasikan \\
$\mathbf{3}$ & Cukup Direkomendasikan \\
$\mathbf{4}$ & Tidak Direkomendasikan \\
$\mathbf{5}$ & Sangat TidakDirekomendasikan \\
\hline
\end{tabular}

Kemudian dilakukan perhitungan untuk mencari waktu tempuh ke setiap lokasi masjid.

Waktu Tempuh $($ jam $)=\operatorname{Jarak}(\mathrm{km}) / \operatorname{Kecepatan}(\mathrm{km} / \mathrm{jam})$
Kemudian dilakukan perhitungan untuk mendapatkan nilai hambatan dengan rumus :

Nilai hambatan $=$ jarak lokasi saat ini ke masjid + jarak masjid ke tujuan awal + (Waktu Tempuh * index kemacetan / 10) + index preferensi.

Dan hasil dari semua nilai hambatan dari lokasi masjid tersebut disorting dan diambil lokasi masjid dengan nilai hambatan yang paling kecil sebagai hasil yang dianggap terbaik berdasarkan algoritma ini. Kemudian sistem akan mengembalikan message ke client berupa data masjid tersebut (latitude ,longitude dan nama masjid).

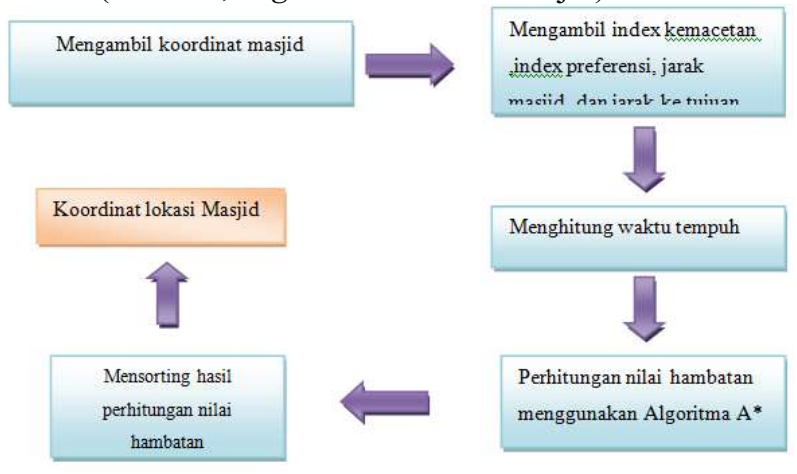

Gambar VII : Proses Pencarian Koordinat Lokasi Masjid di Server

Message balikan yang diterima dari server akan dikonfirmasikan ke pengguna. Setelah pengguna setuju maka lokasi masjid dari message tersebut akan dijadikan lokasi tujuan pada peta di smartphone pengguna memanfaatkan Google API. Namun apabila pengguna tidak setuju maka tidak akan terjadi perubahan arah lokasi tujuan di peta smartphone pengguna.

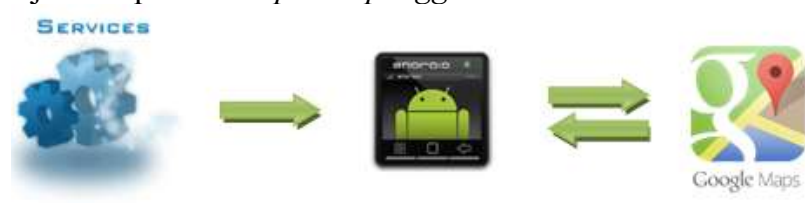

Gambar VIII : Proses Penentuan Koordinat

\section{Result and Discussion}

Sebagai result dari penelitian ini dihasilkan aplikasi web service server sebagai server dan sebuah aplikasi navigasi di android sebagai client.

\section{A. Web Service Server}

Aplikasi ini dibangun dengan bahasa java dan berjalan sebagai service menggunakan Mule Standalone Aplication Server. Web Service ini mempunyai 2 service:

\section{1) Singkronisasi Waktu Sholat}

Sesuai namanya service ini berfungsi untuk menyamakan data waktu shalat di aplikasi navigasi di 
android atau sisi client dengan data server. Sehingga ketika aplikasi navigasi di android menggunakan reminder waktu sholat, sudah merupakan data yang paling baru dan benar. Untuk service ini tidak memerlukan input parameter untuk dapat memanggilnya.

\section{2) Pencarian Lokasi Masjid}

Service ini memiliki fungsi untuk mencari lokasi masjid terbaik dari hasil perhitungan algoritma $A^{*}$ dengan pertimbangan jarak, index kemacetan dan index preferensi masjid. Untuk menggunakan service dibutuhkan input parameter berupa koordinat pengguna saat ini, koordinat tujuan, kecepatan , jarak ke lokasi tujuan dan kode wilayah waktu seperti WIB, WIT dan WITA.

\section{B. Aplikasi Navigasi di Android}

Untuk dapat menjalankan aplikasi navigasi ini dengan baik di smartphone android dibutuhkan akses koneksi internet dan location service pada device tersebut untuk dapat mengakses map dan mendapatkan koordinat posisi saat ini melalui gps.

\section{1) Halaman Utama}

Pada Halaman utama ini sendiri terdapat tiga buah icon menu yaitu, Maps, Info dan setting. Tampilan dari halaman utama ditunjukkan pada gambar di bawah ini.

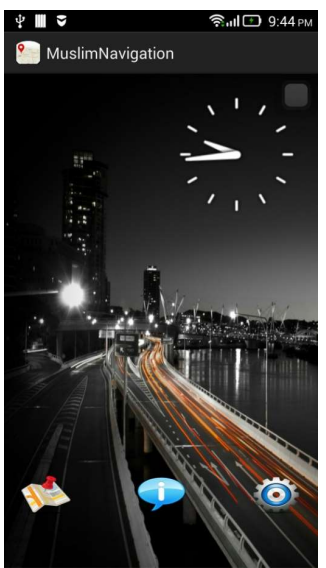

Gambar IX : Tampilan halaman utama aplikasi

\section{2) Map}

Pada Halaman ini yang pertama muncul adalah peta dari google, untuk menampilkan peta tersebut dibutuhkan koneksi internet. Berikut ini adalah tampilan pada halaman maps.

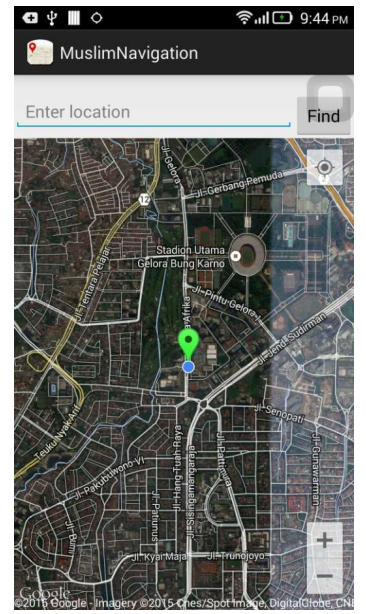

Gambar X : Tampilan Maps.

Pada halaman ini terdapat textfield dan tombol find yang berfungsi untuk mencari lokasi. Pertama kali yang akan tampil di peta pada halaman ini adalah posisi user saat ini, yang digambarkan dengan icon berwarna hijau terang.

\section{3) Proses Menentukan Tujuan}

Pada sistem ini proses menentukan tujuan yang diinginkan dilakukan didalam halaman Maps. Pengguna hanya tinggal menekan agak lama pada titik peta yang diinginkan sebagai tujuan. Pada proses ini aplikasi akan memangil objek json ke google API untuk mendapatkan direction rute menuju tujuan yang tadi kita sudah tentukan dan ditampilkan di peta.

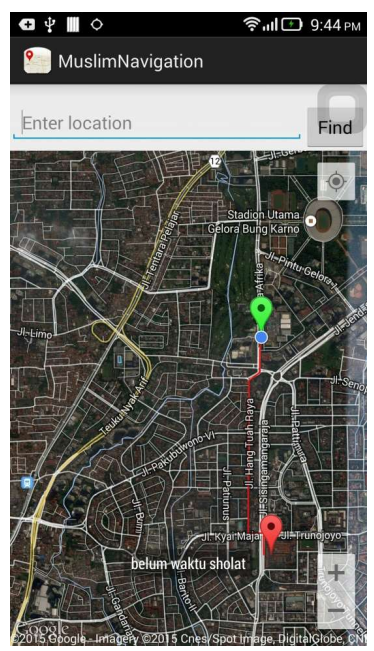

Gambar XI : Tampilan Rute dari Posisi Awal ke Tujuan

4) Proses Reminder Waktu Sholat

Setelah lokasi tujuan ditentukan maka pada saat yang sama reminder waktu sholat berjalan. Proses tersebut 
mengambil waktu sholat dari database yang kemudian di cocokan dengan waktu saat ini. Apabila sesuai maka akan muncul pop-up sebagai notifikasi sudah waktunya sholat. Pengguna akan diberikan pilihan untuk melakukan routing dari tujuan awal ke lokasi masjid atau tidak.

Apabila pengguna memilih 'tidak' maka tidak aplikasi akan tetap menampilkan rute ke tujuan awal di peta. Sedangkan apabila pengguna memilih 'ya', artinya pengguna setuju untuk diarahkan atau dirouting ke lokasi masjid.

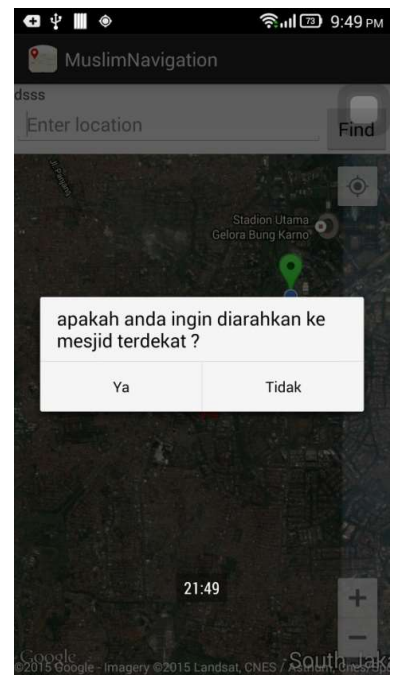

Gambar XII : Tampilan Notifikasi Reminder Waktu Sholat

\section{5) Proses Pencarian Lokasi Masjid}

Pada proses ini aplikasi akan mengambil data untuk dikirimkan sebagai inputan parameter web service, yang kemudian proses pencarian dilakukan di sisi server dan aplikasi kemudian menerima data kembalian dari server. Berdasarkan data yang dikembalikan oleh server tadi ditentukanlah lokasi masjid dan ditampilkan kedalam peta beserta rute menuju kelokasi tersebut dengan bantuan google API.

Apabila pengguna sudah sampai di lokasi masjid tujuan tadi maka akan muncul kembali notifikasi yang berisikan pilihan apakah pengguna ingin dirouting kembali ke lokasi tujuan awal atau tidak. Jika pengguna memilih 'tidak' maka aplikasi tidak akan melakukan apa-apa yang artinya proses selesai. Dan apabila pengguna memilih 'ya' artinya mengguna setuju untuk diarahkan kembali ke tujuan awal, maka aplikasi akan mengambil history tujuan awal tersebut dan menampilkannya kembali kedalam peta.

Proses tersebut akan selesai jika pengguna telah sampai di lokasi tujuan atau pengguna menutup halaman peta.

\section{Pengujian dengan Black Box}

Pada pengujian black box terfokus pada apakah implementasi program memenuhi kebutuhan dari analisis sistem yang telah ditentukan. Pengujian dilakukan dengan menjalankan atau mengeksekusi unit atau modul, kemudian diamati apakah hasil dari unit tersebut sesuai dengan proses yang dikehendaki atau tidak. Proses yang dijadikan objek pada pengujian black box ini terdiri dari proses singkronisasi waktu sholat, menampilkan peta, proses routing ke tujuan, reminder waktu Sholat, pencarian lokasi masjid, proses re-routing dari tujuan awal ke lokasi masjid dan proses re-routing kembali dari lokasi masjid ke tujuan awal:

1) Pengujian proses singkronisasi waktu sholat.

Pengujian ini bermaksud untuk memeriksa apakah proses singkronisasi waktu sholat berjalan dengan baik dan data berhasil terupdate. Berikut ini adalah hasil dari pengujian proses singkronisasi waktu sholat.

Tabel IV : Hasil pengujian black box proses singkronisasi waktu sholat

\begin{tabular}{|l|l|l|l|}
\hline Input & Yang Diharapkan & Hasil Pengamatan & Kesimpulan \\
\hline Menekan menu & a. Jika berhasil data & Data berhasil & Diterima \\
Sikronisasi waktu & terupdate sesuai & terupdate. Apabila & \\
sholat & $\begin{array}{l}\text { dengan data di server. } \\
\text { b. Jika gagal tidak }\end{array}$ & gagal singkronisasi & \\
& tidak terjadi error. & \\
& terjadi error. & & \\
\hline
\end{tabular}

2) Pengujian proses menampilkan peta.

Pengujian ini berfungsi untuk memastikan peta berhasil ditampilkan dengan baik pada aplikasi. Berikut ini adalah hasil dari pengujian proses menampilkan peta.

Tabel V : Hasil pengujian black box proses menampilkan peta

\begin{tabular}{|l|l|l|l|}
\hline Input & Yang Diharapkan & Hasil Pengamatan & Kesimpulan \\
\hline Menekan icon peta & Peta dapat & Peta dapat muncul \\
pada aplikasi. & ditampilkan dengan & Diterima \\
dengan baik selama & \\
baik. & & $\begin{array}{lr}\text { terdapat } \\
\text { internet poneksi } \\
\text { smartphone pada } \\
\text { devicer android } \\
\text { pengguna. }\end{array}$ & \\
& & $\begin{array}{l}\text { Apabila tidak } \\
\text { terdapat koneksi }\end{array}$ & \\
& & internet peta tidak & \\
& & dapat ditampilkan & \\
\hline
\end{tabular}


3) Pengujian proses routing ke tujuan.

Pengujian ini dilakukan untuk memeriksa apakah sistem dapat melakukan routing ke setiap lokasi tujuan yang berbeda. Berikut ini adalah hasil dari pengujian proses routing ke tujuan.

Tabel VI : Hasil pengujian black box proses routing ke tujuan

\begin{tabular}{|l|l|l|l|}
\hline Input & Yang Diharapkan & Hasil Pengamatan & Kesimpulan \\
\hline Menekan suatu & a. Menampilkan icon & a. Icon merah & Diterima \\
lokasi pada peta & merah pada peta & sebagai penanda & \\
sebagai tanda lokasi & tanda lokasi tujuan & \\
tujuan. & dapat ditampilkan & \\
b. Menampikan garis & dengan baik. \\
berwarna merah pada & b. rute ke tujuan & \\
peta sebagai rute ke & pun dapat \\
tujuan. & $\begin{array}{l}\text { ditampilkandengan } \\
\text { baik dengan syarat }\end{array}$ & \\
& & terdapat koneksi \\
internet. & \\
& & c. apabila tidak & \\
& & terdapat koneksi \\
internet maka rute & \\
& & tidak dapat & \\
& & ditampilkan. & \\
\hline
\end{tabular}

4) Pengujian proses reminder waktu Sholat.

Pengujian ini dilakukan untuk memeriksa apakah reminder waktu sholat bekerja ketika dipicu oleh penentuan lokasi tujuan. Berikut ini adalah hasil dari pengujian proses reminder waktu Sholat.

Tabel VII : Hasil pengujian black box proses reminder waktu Sholat

\begin{tabular}{|c|c|c|c|}
\hline Input & Yang Diharapkan & Hasil Pengamatan & Kesimpula \\
\hline $\begin{array}{l}\text { proses routing ke } \\
\text { lokasi tujuan }\end{array}$ & $\begin{array}{l}\text { proses reminder } \\
\text { waktu sholat bejalan } \\
\text { sesuai dengan waktu- } \\
\text { waktunya. }\end{array}$ & $\begin{array}{lr}\text { Reminder } & \text { waktu } \\
\text { sholat } & \text { sudah } \\
\text { berjalan } & \text { sesuai } \\
\text { dengan } & \text { waktu- } \\
\text { waktunya. } & \end{array}$ & Diterima \\
\hline
\end{tabular}

5) Pengujian proses pencarian lokasi masjid.

Pengujian ini dilakukan untuk memeriksa apakah proses pencarian berjalan dan menghasilkan lokasi masjid. Berikut ini adalah hasil dari pengujian proses pencarian lokasi masjid.
Tabel VIII : Hasil pengujian black box proses pencarian lokasi masjid

\begin{tabular}{|c|c|c|c|}
\hline Input & Yang Diharapkan & Hasil Pengamatan & Kesimpulan \\
\hline $\begin{array}{l}\text { Request web } \\
\text { service }\end{array}$ & $\begin{array}{l}\text { a. proses pencarian } \\
\text { dapat berjalan. } \\
\text { b. lokasi masjid yang } \\
\text { dihasilkan sesuai } \\
\text { walau dengan nilai } \\
\text { parameter yang } \\
\text { berbeda-beda }\end{array}$ & 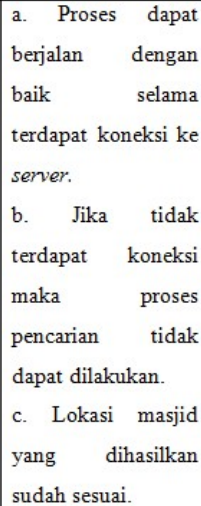 & Diterima \\
\hline
\end{tabular}

6) Pengujian proses re-routing dari tujuan awal ke lokasi masjid.

Pengujian ini dilakukan untuk memeriksa apakah proses re-routing dari tujuan awal ke lokasi masjid berjalan dan tidak terjadi kesalahan routing. Berikut ini adalah hasil dari pengujian proses re-routing dari tujuan awal ke lokasi masjid.

Tabel IX : Hasil pengujian black box proses re-routing dari tujuan awal ke lokasi masjid

\begin{tabular}{|l|l|l|l|}
\hline Input & Yang Diharapkan & Hasil Pengamatan & Kesimpulan \\
\hline Lokasi masjid & a. lokasi masjid dapat & a. Lokasi masjid & Diterima \\
hasil pencarian & ditampilkan di peta. & berhasil & \\
& b. Menampikan garis & ditampilkan dip eta. & \\
berwama merah pada & b. Rute ke lokasi & \\
peta sebagai rute ke & masjid berhasil \\
lokasi masjid. & $\begin{array}{l}\text { ditampilkan selama } \\
\text { ada akses intemet. } \\
\end{array}$ & $\begin{array}{l}\text { c. Rute ke lokasi } \\
\text { masjid tidak tampil } \\
\text { karena tidak ada } \\
\text { koneksi internet. }\end{array}$ & \\
& & & \\
& &
\end{tabular}

7) Pengujian proses re-routing kembali dari lokasi masjid

ke tujuan awal.

Pengujian ini dilakukan untuk memeriksa apakah proses re-routing dari tujuan lokasi masjid ke lokasi tujuan awal berjalan dan tidak terjadi kesalahan routing. Berikut ini adalah hasil dari pengujian proses re-routing kembali dari lokasi masjid ke tujuan awal. 
Tabel X : Hasil pengujian black box proses re-routing kembali dari lokasi masjid ke tujuan awal

\begin{tabular}{|c|c|c|c|}
\hline Input & Yang Diharapkan & Hasil Pengamatan & Kesimpulan \\
\hline $\begin{array}{lr}\text { Kondisi } & \text { telah } \\
\text { sampai di lokasi } \\
\text { masjid } & \\
\end{array}$ & $\begin{array}{l}\text { a. lokasi tujuan awal } \\
\text { dapat ditampilkan } \\
\text { kembali di peta. } \\
\text { b. Menampikan garis } \\
\text { berwama merah pada } \\
\text { peta sebagai rute ke } \\
\text { lokasi tujuan awal. }\end{array}$ & $\begin{array}{l}\text { a. Lokasi tujuan } \\
\text { awal berhasil } \\
\text { ditampilkan dip eta. } \\
\text { b. Rute ke lokasi } \\
\text { tujuan awal } \\
\text { berhasil } \\
\text { ditampilkan selama } \\
\text { ada akses intemet. } \\
\text { c. Rute ke lokasi } \\
\text { tujuan tidak tampil } \\
\text { karena tidak ada } \\
\text { koneksi intemet. }\end{array}$ & Diterima \\
\hline
\end{tabular}

Berdasarkan hasil pengujian black box dapat disimpulkan bahwa sistem yang dikembangkan dapat mengetahui fungsi-fungsi yang salah atau hilang, kesalahan kinerja, inisialisasi dan secara fungsional mengeluarkan hasil yang sesuai dengan yang diharapkan.

\section{Conclution}

Berdasarkan penjelasan yang telah dipaparkan pada bab-bab sebelumnya serta hasil dari pengujian sistem yang dihasilkan pada tahap implementasi maka peneliti mengambil kesimpulan mengenai penelitian sebagai berikut:

1. Rancangan sistem navigasi GPS dengan reminder waktu sholat dapat diimplementasikan menjadi sistem navigasi GPS yang dapat memberikan lokasi masjid terbaik untuk disajikan menjadi aplikasi android berbasis client-server. Pada tahap implementasi sistem disesuaikan dengan kebutuhan dan batasan penelitian.

2. Metode pencarian lokasi masjid dengan Algoritma $A^{*}$ dapat digunakan sebagai metode untuk mencari lokasi masjid terbaik.

3. Aplikasi yang ditawarkan pada penelitian ini dapat memudahkan penggunanya karena cukup dengan menggunakan smartphone android pengguna mendapatkan aplikasi navigasi ke masjid terdekat dan reminder waktu sholat.

\section{References}

[1] [Bagrecha 2012] Bagrecha Komal S., Bramhecha Amit R., Chhajed Sneha S., Khivsara B.A, "Android Application Using GPS Navigation", International Conference on Recent Trends in Engineering \& Technology, ISSN : 2277-9477, 2012

[2] [Booch 1998] Booch., G., "Object Oriented Design and Analysis with application", Addison-Welly, 1998.
[3] [BPS 2010] BPS (Badan Pusat Statistik), "Penduduk Menurut Wilayah dan Agama yang Dianut, Indonesia 2010".

http://sp2010.bps.go.id/index.php/site/tabel?tid=321 \&wid=0. (Diakses 3 Desember 2013).

[4] [Dawson 2009] Dawson, C., W., "Project in Computing and Information System a Student Guide 2nd Edition", Addison-Wesley, 2009.

[5] [Dennis 2005] Dennis,. A, Wixom,. B., H., Tegarden,. D,. "System Analysis and Design with UML v2.0", Wiley, 2005.

[6] [Dharma Kasman 2013] Dharma Kasman, Akhmad. "Kolaborasi Dahsyat Android dengan PHP dan MySql", Lokomedia, Yogyakarta 2013.

[7] [Dennis 2005] Dennis,. A, Wixom,. B., H., Tegarden,. D,. "System Analysis and Design with UML v2.0", Wiley, 2005.

[8] [Galin 2004] Galin D., "Software Quality Assurance", Pearson Education, 2004.

[9] [Geodesy 2011] Teknologi GPS. Dipetik Februari 24,2013, dari geodesy: http://geodesy.gd.itb.ac.id/kkgd/?page_id=498.

[10] [Hart 1968] Hart, P. E.; Nilsson, N. J.; Raphael, B. (1968). "A Formal Basis for the Heuristic Determination of Minimum Cost Paths", IEEE Journal.

[11] [Inrix 2014] INRIX, "Traffic Scorecard Global", http://scorecard.inrix.com/scorecard/ . (Diakses 3 Juni 2013).

[12] [Irawan 2005] Irawan, Budhi, 2005. "Jaringan Komputer", Cetakan Pertama, Graha Ilmu, Bandung.

[13] [Kohari 2004] Kohari, C., R., "Reseach Methodology : Methods and Technique" (second revisited edition), New Age International Publisher, 2004.

[14] [Kompas 2014] Kompas, Budhi, 2005. "Jaringan Komputer", Cetakan Pertama, Graha Ilmu, Bandung.

[15] [Marwan 2004] Marwan Abboud, Lina Mariya Abou Jaoude, Ziad Kerbage, "Real Time GPS Navigation System", Department of Electrical and Computer Engineering, American University of Beirut, Beirut, 2004.

[16] [NIIT 2011] NIIT. "Introducing to Unified Modelling Language" .Sona Printers, 2011.

[17] [Priyanka 2012] Priyanka Shah, Ruta Gadgil, Neha Tamhankar, "Location Based Reminder Using GPS For Mobile (Android)", ARPN Journal of Science and Technology, ISSN : 2225-7217, Volume 2, Issue 4,2012 
[18] [Rathiah 2011] Rathiah Hashim, Mohammad Sibghotulloh Ikhmatiar, Miswan Surip, Masiri Karmin, Tutut Herawan, "Mosque Tracking on Mobile GPS and Prayer Times Synchronization for Unfamiliar Area", International Journal of Future Generation Communication and Networking, Volume 4, Issue 2, 2011

[19] [Religiouspopulation 2013] religion population. http://www.religiouspopulation.com/ (diakses 03 Desember 2013).

[20] [Sanjaya 2005] Sanjaya, Ridwan, SE,S.Kom. 2005. "Membuat Laporan PDF berbasis WEB dengan PHP". PT. Elex Media Komputindo, Jakarta.

[21] [Swati 2012] Swati R. Dhabarde, "Gps Integrated Navigation System", International Journal of Computer Science and Network (IJCSN), ISSN : 2277-5420, Volume 1, Issue 3, 2012.

[22] [Wikipedia 2013] Wikipedia, "Global Positioning System", the free encyclopedia, 2013. http://en.wikipedia.org/wiki/Global_Positioning_Syst em. (Diakses 3 Desember 2013).

[23] [Winarno 2012] Winarno, E. \& Zaki, A., "Membuat Sendiri Aplikasi Android untuk Pemula", 2nd ed., Jakarta: PT Elex Media Komputindo, 2012. 